\title{
Investigation of the structure of wear resistant coatings obtained by plasma powder surfacing
}

\author{
Alexey N. Shapovalov ${ }^{I}$, Olga.B. Kalugina ${ }^{2, *}$, and Roman. R. Dema ${ }^{2}$ \\ ${ }^{1}$ National University of Science and Technology «MISiS», Leninskiy prospekt, 4, 119049, Moscow, Russia \\ ${ }^{2}$ Nosov Magnitogorsk State Technical University, Lenin Avenue, 38, Magnitogorsk city, 455000, Russia
}

\begin{abstract}
The paper studied the structure of the deposited coating, formed on 45 steel with a plasmapowder surfacing wear-resistant white cast iron. The effect of surfacing conditions and other technological influences on the weld pool during surfacing - current modulation, rapid cooling of the weld beads by blowing air and the rapid cooling of the flowing water of the substrate. Tests have been conducted to determine the plasma-powder coating modes of high alloyed wear-resistant coatings which provide in the middle of the metal deposit the structure and properties that ensure maximum wear resistance. Recommendations of using of cooling systems modes has given to obtain an even distribution of microhardness over the fusion zone.
\end{abstract}

\section{Introduction}

Consolidating surfacing of the details of mining machines and metallurgical equipment involves certain technological difficulties. First of all it is connected with excessive tendency of weld metal products to crack formation due to high tension appearing in highly alloyed weld metal and in the welding area. The main reason of the tension in the welding area is the absence of discreteness of the chemical and structural-phase compositions. To avoid cracking plasma-powder surfacing is made at higher values of current and, hence, at maximum melting of metal base and its penetration in the weld metal [1]. It helps to reduce the gradient of the chemical composition in the welding area and as a consequence to reduce the cracking risk. But it leads to strong adulteration of the weld metal with the metal base and finally to the reduction of the performance attributes of the coating structure and increased consumption of expensive surfacing materials. In majority of cases high current and strong metal base melting allows to eliminate the risk of cracking, however the weld metal doesn't meet the requirements to the hardness and wear resistance.

In comparison with the other ways of arc surfacing plasma-powder surfacing of wear resistant coating by twin-arc plasmatron allows to eliminate the chance of cracking the weld metal. It becomes possible due to the effective spending of the plasma arc power on the formation of the molten bath at minimal melting of the metal base thus providing with the preset composition of the weld metal in the first layer of the coating $[2,3]$. At that in the area of weld metal and metal base fusion there appears a durable austenitic interlayer separating base metal from the weld metal [4]. The forming of the austenitic interlayer in the welding area leads to the formation of layered composite coating [5] which in its turn contributes to the increase of the structure discreteness and mechanical properties of the welding area. However, even at optimum modes of welding minimal adulteration of the weld metal with the metal base when plasma-powder surfacing is inevitable [6-8]. Due to the welding in the narrow intermediate area there appears a new transitional alloy with an averaged composition in accordance with the share of the main and the welding materials. At that there are strong concentration gradients of alloying elements, appearing not in the whole area of welding but within the close limits of adjacent diffuse layer and the heat-affected area which can result in cracking as well.

Structural-phase state and performance attributes of intermediate alloys in the welding area will depend on their chemical composition, which can be approximately determined by analysing the corresponding charts [7]. In its turn the chemical composition of the intermediate alloys in the welding area depends on the compositions of the main and weld metal and the level of welding, i.e. mode of plasma-powder surfacing.

In this connection it turns out to be the issue of the day to determine the modes of plasma-powder surfacing with high-alloyed wear-resistant coatings which would ensure maximum wear resistance in the intermediate part of the weld metal, durability and operability in the welding area.

\section{Experimental}

The work investigates the structure of coating of 315X19Ф3 type on steel 45 when plasma-powder surfacing at different modes by applying additional

\footnotetext{
* Corresponding author: kalugina.olga@bk.ru
} 
technological impacts - current modulation. The work also gives evaluation of the current modulation influence on the formed structure as well as phase composition of the weld metal and the welding area.

Plasma-powder surfacing was made by twin arc plasmatron at maximal amperage of the subsidiary arc 40 A. The additive material was the powder, containing $19 \%$ of chromium, vanadium, 3\% (of 315X19Ф3 type), specially developed for wear-resistant plasma-powder surfacing details of mining machines and metallurgical equipment [8]. The surfacing was made on steel 45 patterns according to the modes, indicated in the table1. To adjust the thermal cycle of surfacing and the depth of melting we applied impulse current (current modulation) as well as additional cooling the base by water or blowing.

Table 1. Modes of surfacing

\begin{tabular}{|c|c|c|c|c|c|}
\hline $\begin{array}{l}\text { Mode } \\
\text { of } \\
\text { surfaci } \\
\text { ng }\end{array}$ & $\begin{array}{l}\text { Weld } \\
\text { metal } \\
\text { type }\end{array}$ & $\begin{array}{c}\text { Impulse } \\
\text { ampera } \\
\text { ge, A }\end{array}$ & $\begin{array}{c}\text { Pause } \\
\text { ampera } \\
\text { ge, A }\end{array}$ & $\begin{array}{l}\text { Modula } \\
\text { tion } \\
\text { period, } \\
\text { c }\end{array}$ & $\begin{array}{l}\text { Addition } \\
\text { al effects }\end{array}$ \\
\hline 1 & \multirow{6}{*}{$\begin{array}{c}315 \times 19 \\
\Phi 3\end{array}$} & 120 & - & - & - \\
\hline 2 & & 180 & - & - & - \\
\hline 3 & & 180 & - & - & $\begin{array}{l}\text { Cooling } \\
\text { the base } \\
\text { by water }\end{array}$ \\
\hline 4 & & 120 & 60 & 1 & - \\
\hline 5 & & 180 & 80 & 0,5 & - \\
\hline 6 & & 180 & - & - & Blowing \\
\hline
\end{tabular}

To get the maximal thickness of coating when surfacing powder expenditure was $6 \mathrm{~kg}$ per hour.

\section{Results}

According to [6] when raising the amperage from $120 \mathrm{~A}$ to $180 \mathrm{~A}$, ceteris paribus, the share of the base metal in the coating increases from $3 \%$ to $12 \%$. Under these conditions the welding area becomes the most sensitive to the adulteration with metal base. The microstructure of the welding area is the most sensitive to the modes of surfacing and additional technological impacts and as a consequence becomes an indicator of the share of the metal base in the coating.

When surfacing the powder similar to $315 \mathrm{X} 19 \Phi 3$ at mode 1 with amperage $120 \mathrm{~A}$ there appears a structure of eutectic type in the middle part of the weld metal. The analysis of the difractogram, taken from the middle part of the weld metal, showed 5 lines, related to the matrix latitude (ranet centered cubic lattice) with a parameter $a$ $=3,6081 \AA$, which is a bit greater than the period of pure $\gamma$-iron $a \gamma=3,571 \AA$ [9-11]. The coincidence of the comparative intensity of the matrix lines and the table values of the line intensity for $\gamma$-iron allows to conclude that the matrix of the weld metal is an austenite [10]. Morphological peculiarities also allow to determine it as alloyed $\gamma$-iron.

In the volume of the austenite matrix carbide phase is equally distributed. There are particles of a pencil form distinctive for $\mathrm{M}_{7} \mathrm{C}_{3}$ as well as fan-shaped eutectic on the base of carbide $\mathrm{M}_{7} \mathrm{C}_{3}$ with microsolidity 9400 mega Pascals. The aggregate quantity of carbide phase is 24,5 $\%$ with an averaged distance between carbides equal to 3,37 micrometers (Fig 1).

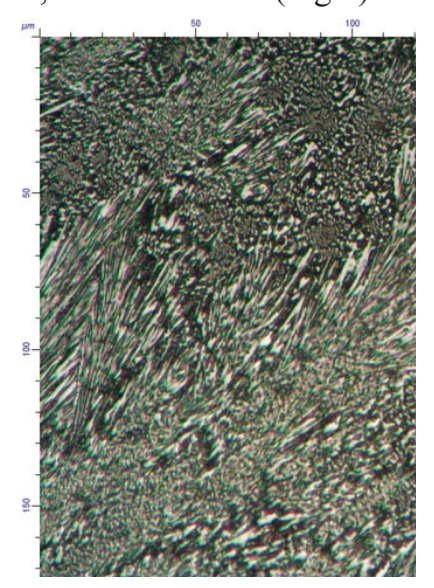

a

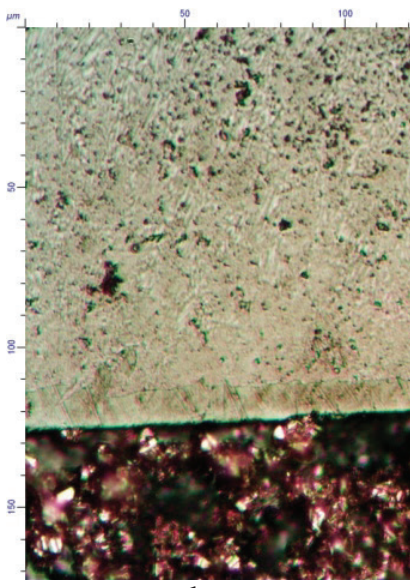

b
Fig 1. Microstructure of coating welded at amperage $120 \mathrm{~A}$ : a - middle part of the weld metal, x500; b - welding area, x500.

The data of metallographic analysis indicate to the presence of light ball-shaped particles in the welding area and the lower part of the middle area of the coating (Fig 2 a). The particles, having similar structure, can be found in the metal base along the welding line (Fig 2 b). The microthickness of the particles in the weld metal is 13000 mega Pascals, but in the metal base it is 12200 mega Pascals. The data of the X-ray structural analysis, microthickness measuring and metallographic analysis allow to come to a conclusion that light ball-shaped particles in the welding area and in the middle part of the middle area are cementite.

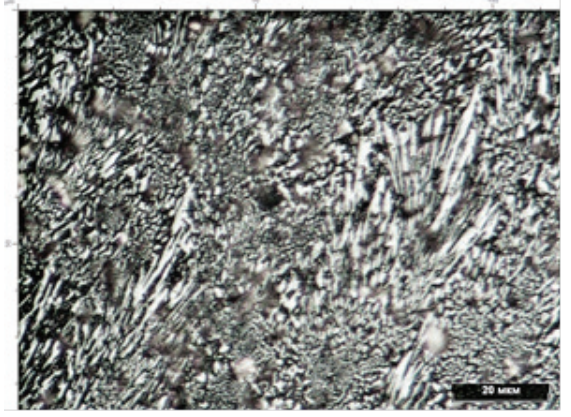

a

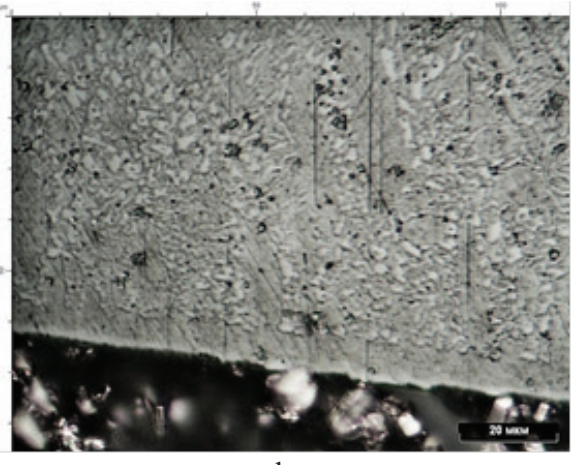

$\mathrm{b}$

Fig 2. Cementite particles in the coating $315 \times 19 \Phi 3$ welded at amperage $120 \mathrm{~A}: \mathrm{a}-$ in the lower part of the middle area, $\mathrm{x} 500$; $\mathrm{b}-$ in metal base, $\mathrm{x} 200$. 
We can suppose that when welding the metal base by arc the molten bath is made by the particles of the additive powder as well as ferrite and perlite grains along the welding line. The cementite laminae of perlite have no time to dissolve in the liquid phase of the molten bath, but coagulate and resurface to a certain altitude, staying in the weld metal. The absence of the metallographically distinguished coagulated particles of cementite in the middle area of the weld metal confirms the supposition that cementite gets to the coating from the metal base as in the process of mixing in the middle part of the coating the cementite released from melted perlite grains dissolves and becomes invisible for metallographic analysis. The presence of cementite causes a negative effect on the wear resistance and performance attributes of the coating, that is why it's necessary to provide such welding modes, in which adulteration with metal base will be minimal.

The powder surfacing of 315X19Ф3 type in the mode 2 at amperage 180 A leads to the formation of the under eutectic structure of coating (Fig 3) instead of the eutectic structure which can appear when surfacing at amperage of $120 \mathrm{~A}$. It can be explained both by a smaller transition coefficient of such alloying elements [8] as carbon and chromium and by a considerable overheating of the molten bath and lower speed of its crystallization. The mentioned processes result in the crystallization of coating, which moves by thalweg in the direction of under eutectic structures [12].

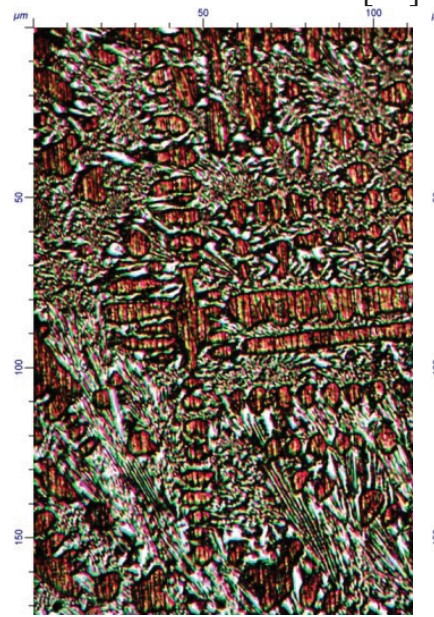

a

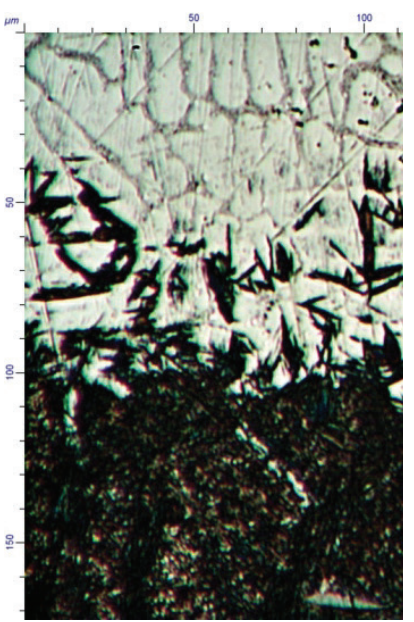

b
Fig 3. Microstructure of the coating welded at amperage 180 A: $\mathrm{a}$ - the middle area of the weld metal, $\mathrm{x} 500$; $\mathrm{b}$ - welding area, $x 500$.

Raising arc pressure when surfacing at amperage $180 \mathrm{~A}$ leads to strong metal base melting and its penetration to the weld metal. As a result in the welding area on the side of the weld metal at $2 . .4$ micrometers distance from the metal base there appears a martensite layer, being on the lines and in the center of crystallites having a dendritic structure. The presence of martensite in the welding area predetermines the tendency of such coating to cracking. In the central part of the weld metal a structure of under eutectic type forms. Austenite dendrites are arranged chaotically, there is no general direction of growth (expansion). It proves a high overheating rate of the central part of the molten bath and low speed of its crystallization. In the interdendritic space there is austenite carbide eutectic of lamellar shape built on the base of chrome carbide similar to $\mathrm{M}_{7} \mathrm{C}_{3}$.

Water cooling of the metal base leads to an accelerated cooling of the coating itself. That is why after surfacing in mode 3 in the welding area there forms an austenite layer $10 \ldots 15$ micrometers thick form which dendrites of $\gamma$-solid solution with ill-defined axes of the second order grow in the direction of the weld metal. The interdendritic space of the weld metal is filled up by highly dispersed triple eutectic on the base of carbides $\mathrm{Cr}_{7} \mathrm{C}_{3}, \mathrm{VC}$ and $\gamma$-solid. The microstructure of the coating is shown at Fig 4.

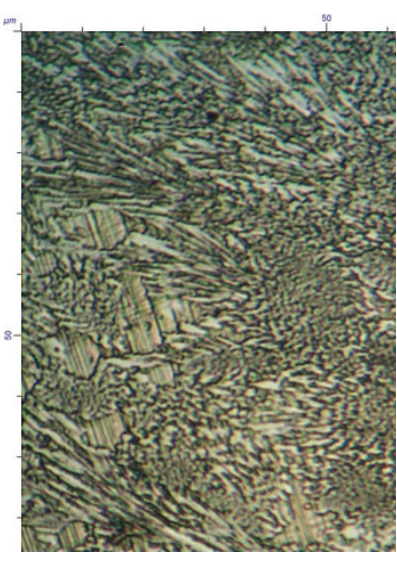

a

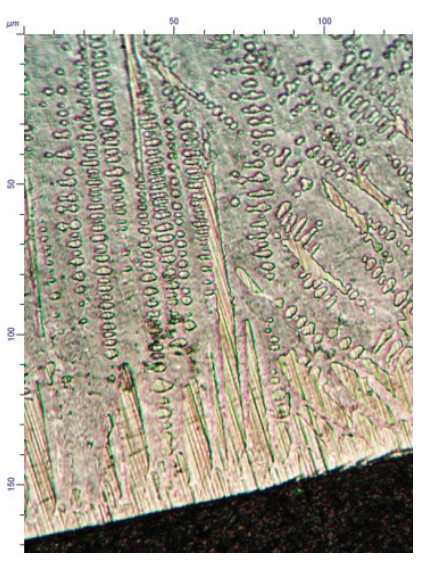

b
Fig 4. The microstructure of the coating made at the amperage 180 A with metal base water cooling: a - middle part of the weld metal, x1000, b - welding area, x500.

The surfacing by a modulated current allows to reduce the overheating rate of the molten bath due to the recurrent deceleration of the welding current from the impulse current to the pause current. At the moment of current impulse metal base melting is taking place and a molten bath is forming (point 2), at the moment of a pause cooling of the molten bath and its size diminishing is happening (point 2). At the moment of plasmatron moving regarding the weld part metal crystallization at lesser degree of heating is being caused [13-15].

The thermal cycle of plasma surfacing can be regulated by changing the parameters of current modulation, i.e. impulse and pause amperage as well as impulse and pause time. As a result of current modulation we see an increase of heat sink of the molten bath, that takes place in the direction perpendicular to the metal base and the environment. The microstructure gets a purposeful character of crystallization, the size of the crystals diminishes and thus the tendency to crystal cracking decreases [16-19].

Due to surfacing in mode 4 at current modulation $120 \backslash 60 \mathrm{~A}$ and frequency $1 \mathrm{~Hz}$ there forms a structure of the welding area (Fig 6) similar to the structure of the welding area at the amperage $120 \mathrm{~A}$ without current modulation. In the middle part of the weld roll there appears a structure, consisting of dendrites $\gamma$-solid solution and austenite and chrome carbide eutectic on the base of chrome carbide of $\mathrm{Me}_{7} \mathrm{C}_{3}$ type. Dendrites of austenite have a purposeful from of growth with 
developed axes of the first order, which can become 100 to 120 micrometers in length and axes of the second order, being 50 ...70 micrometers in length.

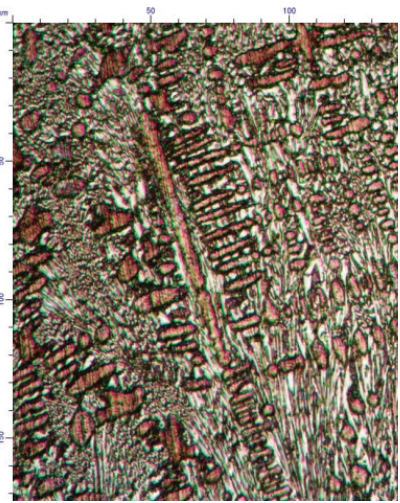

a

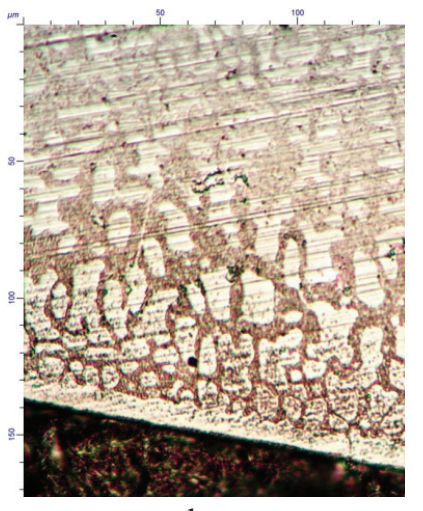

b
Fig 5. Microstructure of the coating made with current modulation $120 \backslash 60 \mathrm{~A}: \mathrm{a}$ - middle part of the weld metal, x 500; $\mathrm{b}$ - welding area, $\mathrm{x} 500$

At that the main axes of dendrites are arranged in the direction perpendicular to the metal base and in the higher layers of the roll in the direction perpendicular to the surface. The greater length of the axes of the second order in comparison with the surfacing in mode 1 is explained by a strict geometrical orientation of the redundant phase of the $\gamma$-solid solution, correlation of the first and the second orders and the absence of interferences in the way of dendritic crystals growing resulting in their considerable size [20-22].

When surfacing with current modulation $180 \backslash 80 \mathrm{~A}$ and frequency $2 \mathrm{~Hz}$ (mode 5) the pressure of the arc on the metal base is maximal among all investigated modes of surfacing. As a result, along with a considerable metal melting one can observe great metal mixing in the welding area and pressing the martensite layer much further from the welding boundary (Fig 6). Along with it the amount of martensite in the welding area decreases to a great extent and the welding area itself becomes extensive and homogeneous in the chemical composition. In the middle of the weld roll there forms a structure consisting of dendrites of $\gamma$-solid solution having a constant orientation regarding each other and the metal base. The main axes of austenite dendrites reach $200 \ldots 250$ micrometers in length and $15 \ldots 20$ micrometers in width. The axes of the second order also reach a great length of $100 . .150$ micrometers and width of 15-20 micrometers correspondingly.

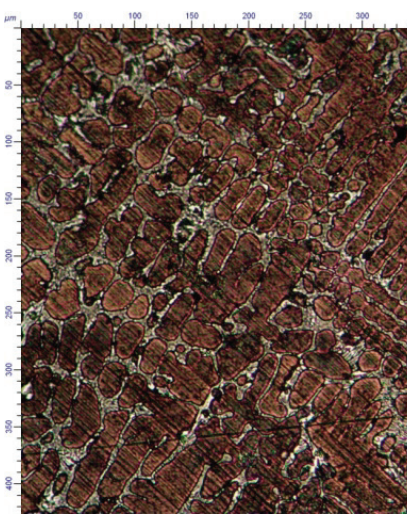

a

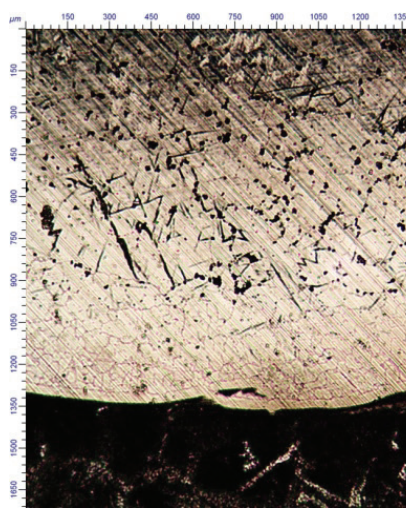

b
Fig 6. Microstructure of coating made with current modulation of $180 / 80 \mathrm{~A}$ : $\mathrm{a}-$ middle part of the weld metal, $\times 500 ; \mathrm{b}-$ welding area, $\times 50$.

In the interdendritic space there is eutectic of lamellar construction $\gamma+\mathrm{Me}_{7} \mathrm{C}_{3}$ with an average interlamellar distance of 4.7 micrometers и microsolidity 4250 mega Pascals, as well as rough carbide laminae of irregular shape, being found mostly on the boundary of eutectic and dendrtic areas.

When surfacing powder of 315X19Ф3 type in mode 6 (general current $180 \mathrm{~A}$, blowing 0,2 mega Pascals), a coating structure of eutectic type is formed (Fig 7). By metallographic analysis one can reveal insignificant quantity of initial carbides $\mathrm{M}_{7} \mathrm{C}_{3}, 3,2 \%$ (Fig 7 b) with an average size in diameter 16,4 micrometers. This little quantity of chrome carbide of $\mathrm{M}_{7} \mathrm{C}_{3}$ type doesn't provoke changes in the eutectic structure in whole. Austenite in its entirety is in eutectic colonies of laminar and rosette structure. Microsolidity of eutectic as well as laminar and rosette structure is similar and comprises 9800 mega Pascals.

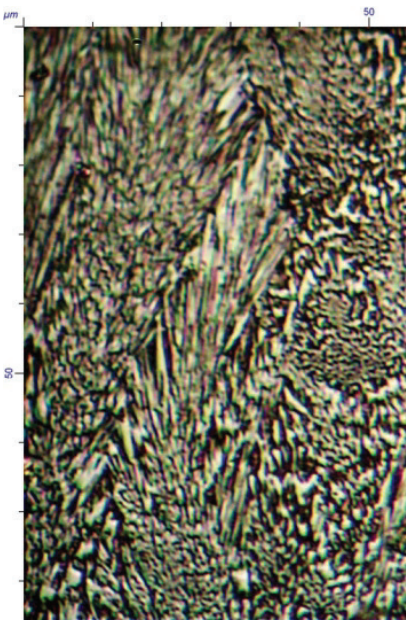

a

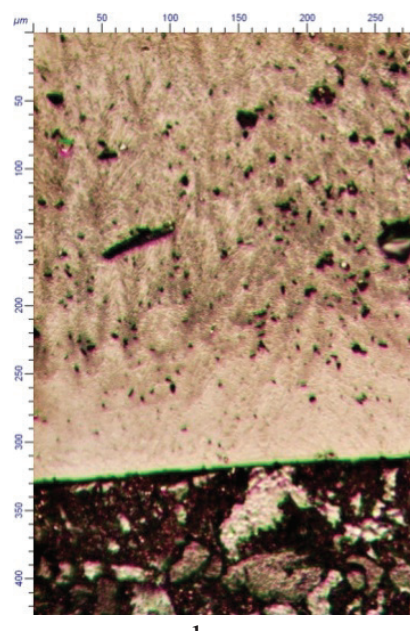

b
Fig 7. Microstructure of the coating made at amperage $180 \mathrm{~A}$ with blowing 0,2 mega Pascals: a - morphology of eutectic, $\times 1000 ; b-$ welding area, $\times 200$.

The plasma powder surfacing with cooling the coating by air causes considerable approaching of carbide particles in eutectic till 1,2 micrometers, and colonies orienting perpendicular to the metal base which 
predetermines high microsolidity of such eutectic and wear-resistance of the coating in whole.

\section{Discussion}

The above stated analysis allows to conclude that introduction of additional technological impacts on the molten bath when plasma-powder surfacing allows to change the course of crystallization of the coating thus changing the type of the formed structure, as due to the introduction of current modulation a structure of eutectic type starts to form. The structure becomes of an eutectic type when being cooled by an air flow under pressure 0,2 mega Pascals.

At that current modulation and accelerated air cooling result in the increase of dispersion of the forming structure and approaching of carbides in eutectic. Intensively weld rolls are cooled by blowing (surfacing mode 6). This mode is also characterized by a considerable overheating of the molten bath above the temperature of liquidus alloy which provides complete dissolution of chrome and vanadium in the melt and formation of dispersed eutectic structure.

Surfacing at amperage 180 A with the introduction of forced cooling of weld metal allows to form a welding area with a gradual transition of properties from the metal base to the weld metal due to the formation of crystallized metal base of high alloyed austenite and absence of martensite in the welding area.

The introduction of current modulation and blowing allows to get an even distribution of microsolidity over welding area due to the formation of crystallized layer consisting of austenite without martensite crystals.

\section{Conclusions}

Surfacing on the current 180 A with the introduction of forced cooling weld metal, fusion zone allows you to create a smooth transition from the properties of the substrate to the weld metal due to the formation of highalloy austenitic crystal layer, and to prevent the formation of martensite in the weld zone.

The introduction of modulation current and air purge allows to obtain a uniform distribution of Micro fusion zone by forming a crystal layer composed of austenite, martensite without the crystals.

More effectively increases the dispersibility structure blowing air cooling roller, as compared with running water cooled substrate.

The authors are thankfully acknowledge the financial support by the Ministry of Education and Science of the Russian Federation for the project № 11.2054.2017/Project task within the framework of the state task for 2017-2019 (Number for publication: $11.2054 .2017 / 4.6)$ to carry out this investigation.

\section{References}

1. A.N. Emelyushin, S.P.Nefedyev. "Investigation of the structure and im pact-abrasive wear resistance of coatings of the FE-C-CR-MN-SI system, additionally alloyed with nitrogen", Welding International. 27, 2. pp. 150-153. (2013).

2. S.P.Nefedyev, R.R Dema., S.A.Nefedyeva, A.V.Yaroslavtcev, "Microstructure of cast iron after plasma bleaching", Journal of Chemical Technology and Metallurgy.50, 2. pp. 213-216. (2015)

3. V.A.Korotkov, "Improvement in arc quenching", Heavy engineering.6. pp. 34-37. (2004).

4. V.A.Korotkov, "Wear resistance of plasmahardened materials", Journal of Friction and Wear.. 32, 1. pp. 17-22. (2011)

5. S.N.Berdnikov, A.E.Pozin, A.A.Podosyan, K.N.Vdovin, "New narrow-wall design for the mold of continuous slab-casting machines", Steel in Translation. 41, 5. pp. 410-412. (2011).

6. Karin Graf, Ana Sofia Clímaco Monteiro D'Oliveira, "Microstructural stability and wear performance of a Ni based alloy PTA coating", Coatings Technology. 106. pp. 156-161. (2002)

7. T. Naguy, J. Kolek and T Anderl, "Engineers Evaluate Cold Spray Coating Processes", J. Therm. Spray. Technol., 14, 3, pp. 300-301.( 2005)

8. N.Ben-Oved, O. Kesler. "A New Technique for the Rapid Manufacturing of Direct Oxidation Anodes for SOFCs", Adv. Mater. Res. 15-17. pp. 287-292. (2007)

9. O.Kesler, "Plasma Spray Processing of Solid Oxide Fuel Cells", Materials Science Forum. 439-543, pp. 1385-1390. (2006).

10. F.Gitzhofer, M.Boulos, J.Heberlein, R.Henne, T.Ishigaki, T.Yoshida, "Integrated Fabrication Processes for Solid-Oxide Fuel Cells Using Thermal Plasma Spray technology", MRS Bulletin. 25. pp. 38-42. (2000)

11. D. Mariotti, P. Maguire, C.M. O.Mahony, and J. A.McLaughlin, "Analysis of excitation processes and electron temperature changes from spectral data in a dc micro plasma discharge", Plasma Sources Sci. Technol., 13, 4, p. 576-581, Nov. (2004).

12. J. G. Eden and S.-J. Park, «Microcavity plasma devices and arrays: A new realm of plasma physics and photonic applications,» Plasma Phys. Control. Fusion, 47, 12, p. 83-92, Dec. (2005).

13. José Roberto Tavares Branco, Robert Gansert, Sanjay Sampath Christopher C. Berndt, Herbert Herman, "Solid Particle Erosion of Plasma Sprayed Ceramic", Coatings Materials Research, 7, 1, pp. 147-153.(2004)

14. H. T.Fan, and Wu, S. M., 1995, "Case studies on modeling manufacturing processes using artificial neural networks". Journal of Engineering for Industry, 117, p. 412-417.

15. K.N.Vdovin, D.A.Gorlenko, A.N.Zavalishchin, "Influence of industrial tempering on the composition of complex cast iron". Steel in Translation. 43, 5. pp. 288-290. (2013)

16. K.N Vdovin., D.A.Gorlenko, A.N.Zavalishchin, "Carbide transformations in tempering of complexly 
alloyed white cast iron", Metal Science and Heat Treatment. 57, 5. (2015)

17. S.V.Anakhov, Y.A Pykin, "Comparative analysis of gas-dynamic factors at the noise radiation of plasmatrons". Welding production. 1, pp. 31-36. (2005)

18. S.V.Anakhov, "Effect og active gas mixtures on the efficiency of plasma surface hardening", Welding International. 27, 1. pp. 77-82. (2013)

19. S.V.Anakhov, Y.A Pykin., S.A Shakurov., "Structural-functional principles of design in electric plasma technologies", Welding International. 28, 7. pp. 579-582. (2014).

20. A.N. Yemelyushin, A.B.Sychkov, V.P.Manin, M.A.Sheksheyev, "Investigation of the structure and mechanical properties of welded joints in steels of the K56 strength grade in different welding conditions", Welding International. 28, 1. pp. 70-74. (2014)

21. A. Nady, H. Bonnefoy, V. Klosek, M. H. Mathon, A. Lodini and A. Baczmanski, "Finite element analysis and neutron diffraction evaluation of residual stresses in satellite coating produced by PTA process", JCPDS-International Centre for Diffraction Data. pp. 454-461. (2009)

22. A.Zikin, S. Ilo, P.Kulu, I.Hussainova, C.Katsich, E. Badisch, "Plasma tra nsferred arc hardfacing of recycled hardmetal reinforced nickel-matrix surface composites", Mat. Sci. (Medžiagotyra), 18, pp. 1217. (2012) 